\title{
Realistic circuit modeling: large-scale simulations of the cerebellar granular layer
}

\author{
Sergio Solinas ${ }^{1,2^{*}}$, Thierry Nieus ${ }^{3}$, Fabio Crotta ${ }^{1}$, Stefano Masoli ${ }^{1}$, Egidio D'Angelo ${ }^{1,2}$ \\ From Nineteenth Annual Computational Neuroscience Meeting: CNS*2010 \\ San Antonio, TX, USA. 24-30 July 2010
}

The granular layer network structure was generated on the basis of anatomical and functional information to a high level of detail and using detailed "realistic" models of neurons and synapses, which include biophysical details at the membrane, channel and receptor level [1-4]. The cerebellar granular layer has been proposed since far to perform spatio-temporal transformations on incoming signals to be relayed to Purkinje cells. However, the nature of such operations remained elusive. Here, by combining advanced observations at the molecular/cellular level with a detailed description of the network structure, we have developed a realistic computational model of the granular layer network and explored its internal dynamics. The network implemented the feed-forward and feed-back inhibitory loops formed by mossy fibers, granule cells and Golgi cells respecting specific connectivity rules and yet allowing for a certain degree of randomness. The network generated noisy background spontaneous activity and was activated using patterns inspired to those recorded in vivo. The response of the model to input bursts consisted in new granule cell bursts composed of a few high-frequency spikes limited in time (time windowing effect) and space (center-surround effect) by network inhibition. Due to the presence of NMDA receptors and other ionic mechanisms, this burst-burst transmission process showed a marked frequency-dependence generating a high-pass filter with a cut-off frequency around $50 \mathrm{~Hz}$. The specific connection geometry, which includes overlapping and clustering of the multiple inhibitory fields of Golgi cells, determined activation of specific granule cell subsets enhancing time-windowing and center-surround. When the model was bombarded with a random mossy fiber discharge, it showed the

\footnotetext{
* Correspondence: dangelo@unipv.it

'Dept. of Physiology, University of Pavia and CNISM, Via Forlanini 6, I-27100 Pavia, Italy
}

emergence of sustained coherent oscillations in the theta-frequency band. Thus, the simulations match the most relevant experimental observations reported so far and predict the contribution of various elements to network activities. It is of relevance that, in these simulations, granule cell activation remained sparse not just at rest but also during burst-burst transmission and during coherent population activity. This model represents the basis for investigating the spike codes transmitted through the cerebellar granular layer to Purkinje cells and for further extensive simulations of cerebellar network processing.

\section{Acknowledgements}

This work was supported by projects SENSOPAC (FP6-IST 028056) and CYBERRAT (Bio-ICT convergence 216528) of the European Commission and by NEUROIMAGE of CNISM (Consorzio Interuniversitario per le Scienze Fisiche della Materia). The computational facility for the most intensive simulations was provided by the parallel cluster CASPUR (Consorzio Interuniversitario per le Applicazioni di Supercalcolo per Università e Ricerca).

\section{Author details}

${ }^{1}$ Dept. of Physiology, University of Pavia and CNISM, Via Forlanini 6, I-27100 Pavia, Italy. ${ }^{2}$ Brain Connectivity Center, Istituto Neurologico IRCCS fondazione C. Mondino, Via Mondino 2, I-27100 Pavia, Italy. ${ }^{3}$ Neuroscience and Brain Technology, Italian Institute of Technology (IIT), Via Morego 30, 16163 Genova, Italy.

Published: 20 July 2010

\section{References}

1. D'Angelo E, Nieus T, Maffei A, Armano S, Rossi P, Taglietti V, Fontana A, Naldi G: Theta-frequency bursting and resonance in cerebellar granule cells: experimental evidence and modeling of a slow $\mathrm{K}^{+}$-dependent mechanism. J Neurosci 2001, 21:759-770.

2. Nieus T, Sola E, Mapelli J, Saftenku E, Rossi P, D’Angelo E: LTP regulates burst initiation and frequency at mossy fiber-granule cell synapses of rat cerebellum: experimental observations and theoretical predictions. J Neurophysiol 2006, 95:686-699.

3. Solinas S, Forti L, Cesana E, Mapelli J, De Schutter E, D'Angelo E: Computational reconstruction of pacemaking and intrinsic electroresponsiveness in cerebellar golgi cells. Front Cell Neurosci 2007, 1:2, doi10.3389/neuro.03.002.2007. 
4. Solinas S, Forti L, Cesana E, Mapelli J, De Schutter E, D'Angelo E: Fast-reset of pacemaking and theta-frequency resonance patterns in cerebellar golgi cells: Simulations of their impact in vivo. Front Cell Neurosci 2007, 1:4, doi10.3389/neuro.03.004.

doi:10.1186/1471-2202-11-S1-P117

Cite this article as: Solinas et al:: Realistic circuit modeling: large-scale simulations of the cerebellar granular layer. BMC Neuroscience 2010 11(Suppl 1):P117.

Submit your next manuscript to BioMed Central and take full advantage of:

- Convenient online submission

- Thorough peer review

- No space constraints or color figure charges

- Immediate publication on acceptance

- Inclusion in PubMed, CAS, Scopus and Google Scholar

- Research which is freely available for redistribution

Submit your manuscript at www.biomedcentral.com/submit 